\title{
CRYOTHERAPY DAN INTENSITAS NYERI PADA INJEKSI INTRAKUTAN
}

\author{
Evelin Malinti 1*, Febri A. Nabuasa 2 \\ 1. Fakultas Ilmu Keperawatan, Universitas Advent Indonesia \\ *email: evelin.malinti@unai.edu
}

\begin{abstract}
Abstrak
Cryotherapy merupakan aplikasi terapi suhu rendah atau dingin yang digunakan untuk berbagai keperluan seperti mengurangi pembengkakan pada trauma, peradangan dan mengurangi nyeri. Cryotherapy juga telah digunakan untuk menangani nyeri pada prosedur penyuntikan seperti penyuntikan subkutan dan intravena. Secara khusus penelitian ini bertujuan untuk mengevaluasi perbedaan efek dari cryotherapy kering dan basah pada intensitas nyeri injeksi intrakutan. Metode: yang digunakan dalam penelitian ini adalah quasi ekperimen dengan post-test design. Pemilihan sample menggunakan teknik purposive sampling untuk memperoleh total 54 responden yang dibagi kedalam dua kelompok. Penelitian ini membandingkan intensitas nyeri kedua kelompok menggunakan numerical pain rating scale. Masing-masing kelompok mendapatkan aplikasi cryotherapy pada area penyuntikan selama 5 menit sebelum dilakukan injeksi intrakutan. Kelompok I diberikan aplikasi cryotherapy dalam bentuk es batu dalam plastik es yang dibungkus kantong kain. Kelompok II diberikan aplikasi washlap yang telah dicelupkan dalam air es. Hasil penelitian menunjukkan bahwa rata-rata intensitas nyeri pada kelompok I berada pada kategori nyeri sedang, dan kelompok II berada pada kategori nyeri berat terkontrol. Uji t-independen menunjukkan bahwa terdapat perbedaan signifikan pada intensitas nyeri diantara kedua kelompok $(\mathrm{p}<0.05)$. Dengan demikian aplikasi cryotherapy dengan es batu selama 5 menit lebih efektif mengurangi intensitas nyeri pada injeksi intrakutan. Penelitian lebih lanjut dapat dilakukan menggunakan alat ukur berbeda terhadap intesitas nyeri seperti verbal rating scale atau painaid scale.
\end{abstract}

Kata kunci: cryotherapy, injeksi intrakutan, intensitas nyeri

\section{Abstract}

Cryotherapy is an application of low or cold temperature therapy that is used for various purposes such as reducing swelling in trauma, inflammation and reducing pain. Cryotherapy has also been used to treat pain in injection procedures such as subcutaneous and intravenous injections. In particular, this study aimed to evaluate the differences in the effects of dry and wet cryotherapy on the pain intensity of intracutaneous injection. The method used in this study is quasi experiment with post-test design. The sample selection uses a purposive sampling technique to obtain a total of 54 respondents divided into two groups. This study compared the intensity of pain between the two groups using the numerical pain rating scale. Each group received an application of cryotherapy in the injection area for 5 minutes before intracutaneous injection. Group I was given the application of cryotherapy in the form of ice cubes in ice plastic wrapped in a cloth bag. Group II was given the washlap application which had been dipped in ice water. The results showed that the average pain intensity in group I was in the moderate pain category, and group II was in the category of heavily controlled pain. Independent $t$-test showed that there were significant differences in pain intensity between the two groups ( $p<0.05)$. Thus the application of cryotherapy with ice cube for 5 minutes is more effective in reducing pain intensity in intracutaneous injection. Further research can be done by using different measuring instruments for pain intensity such as the verbal rating scale or painaid scale.

Keywords: cryotherapy, intracutaneous injection, pain intensity 


\section{Pendahuluan}

Nyeri merupakan keluhan umum yang sering menjadi alasan individu untuk mendapatkan layanan kesehatan. Namun, beberapa tindakan medis yang dilakukan untuk menangani masalah kesehatan juga bisa menimbulkan rasa nyeri. Penanganan nyeri terus menjadi hal yang menarik dan penting untuk meningkatkan rasa nyaman individu yang mengalami masalah kesehatan atau yang menerima tindakan keperawatan.

Prosedur keperawatan seperti pemberian obat injeksi merupakan tindakan yang dapat menimbulkan nyeri. Tidak sedikit individu yang merasa takut dengan tindakan injeksi, bahkan banyak yang menghindari tindakan medis yang mencakup tindakan injeksi (Wright, Yelland, Heathcote, Ng, \& Wright, 2009). Perawat sebagai pemberi asuhan keperawatan bertanggungjawab meminimalisasikan efek nyeri dari prosedur yang menyakitkan seperti tindakan injeksi.

Injeksi intrakutan merupakan salah satu injeksi yang menyakitkan. Injeksi intrakutan dilakukan untuk uji sensitivatas termasuk uji tuberkulin dan alergi. Jenis injeksi ini dilakukan dengan menyuntikan bahan/obat dikulit yang disebut dermis (Mubarak, Indrawati, \& Susanto, 2015; Lynn, 2011). Nyeri yang dirasakan akibat penyuntikan intrakutan merupakan nyeri yang tergolong sebagai nyeri periferal, karena stimulus nyeri berada di permukaan tubuh (Sutanto \& Fitriana, 2017). Secara anatomi pada area dermis terdapat ujungujung saraf perifer sehingga injeksi intrakutan menimbulkan efek nyeri yang cukup menyakitkan (Nurachmah, 2017)

Salah satu cara yang dapat dilakukan untuk menangani nyeri adalah dengan cryotherapy. Cryotherapy merupakan aplikasi suhu rendah atau terapi dingin yang digunakan pada penanganan nyeri (Rastogi, 2018). Terapi dingin ini merupakan terapi modalitas pilihan pada trauma akut dan subakut karena efektifitas fisiologis pada jaringan yang mengalami trauma (Freire, Geremia, Baroni, \& Vaz, 2016).

Sharma dan Khandpur (2009), mengklaim bahwa cryotherapy mudah dilakukan, aman dan tidak membutuhkan biaya yang besar. Walaupun cryotherapy memiliki kemungkinan resiko efek yang tidak dinginkan seperti ice-burn, injuri pada saraf, mengurangi rentang gerak dan reaksi alergi, namun dapat dihindari dengan mengikuti petunjuk penggunaan terapi ini. Durasi aplikasi suhu dingin tergantung area jaringan yang dimaksud untuk diberi terapi dan tujuan pemberian pendinginan. Pendinginan yang dimaksudkan untuk mengurangi nyeri dapat menggunakan es yang dibungkus dalam waktu sekitar 5 menit (Hoens \& Paul, 2013).

Praktek aplikasi suhu dingin harus dilakukan dengan hati-hati pada lanjut usia dan tidak dianjurkan dilakukan pada individu yang memiliki gangguan pembuluh darah atau yang hipersensitif terhadap suhu dingin. Aplikasi cryotherapi yang tepat memberi manfaat yang lebih besar dari efek samping yang mungkin terjadi. Cryotherapi dengan berbagai metode dapat memberi manfaat mengurangi nyeri, membatatasi perluasan peradangan, dan mengontrol edema. (Hoens \& Paul, 2013). Beberapa penelitian menunjukkan bahwa cryotherapy efektif dalam mengurangi respon peradangan pada hewan percobaan (Ramos, et al., 2016; Bleakley \& Davidson, 2010) dan pada pasien dengan penyakit peradangan (Stanek, Cholewka, Wielkoszynski, Romuk, \& Sieron, 2018; Guilot, et al., 2014). Penggunaan terapy dingin juga efektif dalam menangani nyeri pada fibromyalgia (Rivera, Tercero, salas, Gimeno, \& Alejo, 2018), nyeri yang 
dirasakan saat melahirkan (Vagens, Nunes, da Silva, \& Progianti, 2016).

Cryotherapy juga mengurangi nyeri pada beberapa prosedur penyuntikan. Pemberian terapi dingin pada area injeksi anastesi lokal sebelum dilakukan penyuntikan memberi efek berkurangnya rasa sakit saat penyuntikan (Mahshidfar, et al., 2016). Pemberian terapi dingin sebelum injeksi subkutan dan intramuskular juga mengurangi intensitas nyeri pada saat penyuntikan (El-Deen \& Youssef, 2018; Ramadan, El-fouly, Sharaf, \& Ayoub, 2016). Bahkan pasien anak yang menjalani terapi hemodialisa yang diberi es beku dalam plastik pada area penyuntikan arteriovenous fistula, menunjukkan rasa nyeri yang rendah (Attia \& Hassan, 2017).

Pada penyuntikan intarkutan, banyak klien yang mengeluhkan nyeri yang hebat saat obat disuntikan. Namun belum ada intervensi khusus untuk mengurangi nyeri ini. Penelitian ini, bertujuan untuk mengetahui efek dari aplikasi cryotherapy pada intensitas nyeri yang dirasakan saat penyuntikan intrakutan.

\section{Bahan dan Metode Penelitian}

Penelitian ini menggunakan metode quasi-eksperimen dengan post-test design. Sampel penelitian dipilih dengan teknik purposive sampling, yaitu klien yang menerima injeksi intrakutan yang berusia dewasa muda (18-20 tahun), yang tidak memiliki riwayat penyakit pembuluh darah ataupun alergi terhadap suhu dingin dan bersedia ikut serta dalam penelitian dengan menandatangani informed consent. Data deskriptif dianalisa dengan mencari mean dan data bivariat dianalisa dengan SPSS menggunakan uji t-independen.

Responden dibagi dalam 2 kelompok intervensi. Kelompok I mendapatkan aplikasi cryotherapy kering dari bahan es batu yang di pak dalam plastik dan dimasukan dalam sarung yang terbuat dari kain. Kelompok II mendapatkan aplikasi cryotherapy basah yang disiapkan dengan cara menggunakan washlap dingin yang telah dicelupkan kedalam air es. Kedua kelompok diberi terapi kering maupun basah selama 5 menit dengan diukur menggunakan stopwacth pada area penyuntikan intrakutan yaitu di lengan bawah bagian dalam sebelum dilakukan penyuntikan.

Intensitas nyeri diukur dengan numerical pain rating scale (0-10) berdasarkan pernyataan responden, dengan rentang: $0=$ tidak nyeri, $1-3=$ nyeri ringan, 4-6 = nyeri sedang, 7-9 = nyeri berat terkontrol, $10=$ nyeri berat tidak terkontrol

Peralatan injeksi intrakutan yang digunakan adalah syringe 1cc dengan needle $23 \mathrm{G}$. Obat yang diinjeksikan adalah antibiotik ceftriaxon yang didilute dengan aqua bides. Area penyuntikan dibersihkan dengan alkohol swap. Setiap responden diinjeksikan sebanyak $0,1 \mathrm{cc}$ cairan antibiotik yang telah didilute 1:9.

\section{Hasil}

Sebanyak 54 responden yang ikut serta dalam penelitian dan dibagi kedalam 2 kelompok intervensi. Masing-masing kelompok terdiri dari 27 responden yang berjenis kelamin laki-laki dan perempuan. Distribusi responden berdasarkan intensitas nyeri dan jenis kelamin pada kedua kelompok ditunjukkan dalam tabel 1 . 
Tabel. 1 Distribusi responden berdasarkan intensitas nyeri dan jenis kelamin pada kedua kelompok

\begin{tabular}{|c|c|c|c|c|c|}
\hline \multirow{2}{*}{\multicolumn{2}{|c|}{ Karakteristik }} & \multicolumn{2}{|c|}{$\begin{array}{l}\text { Es yang } \\
\text { dipak }\end{array}$} & \multicolumn{2}{|c|}{$\begin{array}{l}\text { Washlap } \\
\text { yang dicelup } \\
\text { di air es }\end{array}$} \\
\hline & & $\mathrm{N}$ & $\%$ & $\mathrm{~N}$ & $\%$ \\
\hline \multirow{5}{*}{$\begin{array}{l}\text { Intensita } \\
\text { s nyeri }\end{array}$} & $\begin{array}{l}\text { Tidak } \\
\text { nyeri }\end{array}$ & - & - & - & - \\
\hline & $\begin{array}{l}\text { Nyeri } \\
\text { ringan }\end{array}$ & 12 & 44 & - & - \\
\hline & $\begin{array}{l}\text { Nyeri } \\
\text { sedang }\end{array}$ & 7 & 26 & 5 & 19 \\
\hline & $\begin{array}{l}\text { Nyeri } \\
\text { berat } \\
\text { terkont } \\
\text { rol }\end{array}$ & 7 & 26 & 16 & 59 \\
\hline & $\begin{array}{l}\text { Nyeri } \\
\text { berat } \\
\text { tidak } \\
\text { terkont } \\
\text { rol }\end{array}$ & 1 & 4 & 6 & 22 \\
\hline \multirow[t]{2}{*}{$\begin{array}{l}\text { Jenis } \\
\text { kelamin }\end{array}$} & $\begin{array}{l}\text { Laki- } \\
\text { laki }\end{array}$ & 9 & 33 & 12 & 44 \\
\hline & $\begin{array}{l}\text { Peremp } \\
\text { uan }\end{array}$ & 18 & 67 & 15 & 56 \\
\hline
\end{tabular}

Perbedaan rata-rata intensitas nyeri antara kedua kelompok dapat dilihat dalam tabel 2. Perbedaan rata-rata intensitas nyeri dilakukan dengan uji t-independen.

Tabel 2 Intensitas nyeri pada kelompok es yang dipak dan kelompok washlap yang dicelupkan di air es.

\begin{tabular}{|c|c|c|c|c|c|}
\hline $\begin{array}{l}\text { Kelompo } \\
\text { k }\end{array}$ & Min & Max & $\begin{array}{l}\text { Mea } \\
\text { n }\end{array}$ & SD & $\mathbf{p}$ \\
\hline $\begin{array}{l}\text { Es yang di } \\
\text { pak }\end{array}$ & 1 & 10 & 4.88 & $\begin{array}{l}2,6 \\
6\end{array}$ & .000 \\
\hline $\begin{array}{l}\text { Washlap } \\
\text { yang } \\
\text { dicelup di } \\
\text { air es }\end{array}$ & 5 & 10 & 7,88 & $\begin{array}{l}1,6 \\
0\end{array}$ & \\
\hline
\end{tabular}

Perbedaan rata-rata intensitas nyeri pada kedua kelompok berdasarkan jenis kelamin ditunjukkan dalam tabel 3, menggunkan uji t independen.

Tabel 3 Perbedaan rata-rata intensitas nyeri berdasarkan jenis kelamin

\begin{tabular}{lllll}
\hline Kel & JK & $\begin{array}{l}\text { Mea } \\
\text { n }\end{array}$ & SD & p \\
\hline $\begin{array}{l}\text { Es } \\
\text { yang di }\end{array}$ & Perempu & 5,16 & $\begin{array}{l}2,54 \\
\text { pak }\end{array}$ & $\begin{array}{l}.45 \\
5\end{array}$ \\
& Laki-laki & 4,33 & $\begin{array}{l}2,95 \\
8\end{array}$ &
\end{tabular}

\begin{tabular}{lllll} 
Washla & Perempu & 7,93 & 1,62 & .87 \\
$\begin{array}{l}\text { p yang } \\
\text { dicelup }\end{array}$ & an & & 4 & 6 \\
$\begin{array}{l}\text { di air es } \\
\text { Laki-laki }\end{array}$ & 7,83 & 1,64 & 2 \\
\hline
\end{tabular}

Pembahasan

Data deskriptif dari kedua kelompok pada tabel 1 menunjukkan bahwa distribusi intensitas nyeri pada kelompok yang menerima aplikasi es yang dipak, sebanyak 1 orang responden (4\%) mengalami nyeri berat tidak terkontrol, sebanyak 7 orang responden (26\%) mengalami nyeri berat terkontrol, 7 orang responden $(26 \%)$ mengalami nyeri intensitas sedang, dan 12 orang responden (44\%) mengalami nyeri dengan intensitas ringan. Pada kelompok yang menerima aplikasi washlap yang dicelup di air es terdapat 6 orang responden (22\%) mengalami nyeri berat tidak terkontrol, 16 orang responden $(59 \%)$ mengalami nyeri berat, dan 5 orang responden (19\%) mengalami nyeri dengan intensitas sedang.

Ambang batas nyeri dan toleransi nyeri setiap individu berbeda. Ambang batas nyeri merupakan poin dimana stimulus nyeri dirasakan sebagai nyeri. Sedangkan toleransi nyeri lebih kepada 
intensitas maksimum atau durasi nyeri yang ingin ditahan atau ditanggung sebelum suatu tindakan untuk menghilangkan nyeri dilakukan (Port, 2011). Nyeri yang dirasakan oleh masing-masing individu dipengaruhi faktor fisik seperti peradangan diarea injuri, kelelahan, dan kurang tidur. Faktor lain seperti pengalaman nyeri sebelumnya, faktor emosi seperti rasa cemas atau rasa takut, situasi dimana rasa nyeri itu muncul, usia, jenis kelamin, dan sosial budaya juga mempengaruhi persepsi dan sensitivitas nyeri seseorang (Daniels \& Nicoll, 2012).

Pada tabel 2 ditunjukkan rentang intensitas dan rata-rata serta perbedaan nyeri kedua kelompok. Kelompok yang menerima aplikasi es yang di pak memiliki rentang intensitas ringan (1) sampai berat tidak terkontrol (10). Sedangkan intensitas nyeri yang dirasakan oleh kelompok yang menerima aplikasi washlap yang dicelup di air es memiliki rentang dari intensitas nyeri sedang (5) sampai nyeri berat tidak terkontrol (10). Rata-rata intensitas nyeri pada kelompok yang menerima aplikasi es batu yang di pak adalah 4,88 dan kelompok yang menerima aplikasi washlap yang dicelup di air es adalah 7.88. Intensitas nyeri yang dirasakan oleh responden di kelompok es batu yang di pak pada saat penyuntikan intrakutan dikategorikan sebagai nyeri sedang. Sedangkan intensitas nyeri yang dirasakan oleh responden dikelompok washlap yang dicelup di air es pada saat dilakukan penyuntikan intrakutan dikategorikan sebagai nyeri berat terkontrol. Hasil uji t-independent menunjukkan bahwa $\mathrm{p}=.000$. Hal ini mengindikasikan bahwa terdapat perbedaan yang signifikan pada intensitas nyeri yang dirasakan diantara kedua kelompok.

Hasil penelitian ini menunjukkan bahwa aplikasi cryotherapy kering menggunakan es batu yang dibungkus dalam kantong kain memberi efek meringankan nyeri yang dirasakan saat dilakukan penyuntikan intrakutan dibandingkan dengan aplikasi cryotherapy basah dengan washlap yang telah dicelupkan di air es. Penelitian yang dilakukan kurang lebih 30 tahun lalu membandingkan efek es kering dan es basah untuk mendinginkan kulit menunjukkan bahwa es kering lebih efektif (Belitsky, Odam, \& Hubley-Kozey, 1987). Penggunaan air es (es basah) dibandingkan dengan penggunaan gel beku (es kering) sebagai metode cryotherapy menunjukkan bahwa pengguaan gel lebih efisien dalam memberi efek dingin dan anti nyeri (Leventhal, Cianchi, \& de Oliveira, 2010).

Rastogi (2018) menjelaskan bahwa fisiologi cryotherapy pada nyeri adalah dengan meningkatkan ambang batas nyeri dan mengurangi sensasi nyeri melalui mekanisme gate control, dan mengurangi velositas konduksi saraf sensory. Hal ini sesuai dengan penelitian yang dilakukan oleh Yoon (2008) yang menemukan bahwa pemberian kompres es batu dapat secara signifikan lebih efektif menurunkan nyeri intra kutan pada prosedur skin test untuk pemberian antibiotik.

Aplikasi terapi dingin menggunakan es batu sebagai upaya untuk mengurangi intensitas nyeri pada imunisasi bayi juga terbukti efektif (Fiktri \& Khusnul, 2011). Hasil penelitian Ramdhanie (2018) menunjukkan bahwa penanganan nyeri saat penyuntikan intravena dapat dilakukan dengan pemberian kompres dingin. Pada prosedur pemasangan infus anak, kompres dingin dibandingkan dengan kompres hangat terbukti efektif meminimalisasi nyeri (Indriyani, Hayati, \& Chodidjah, 2013).

Hasil uji perbedaan intensitas nyeri pada kedua kelompok berdasarkan jenis 
kelamin (tabel 3) menunjukkan bahwa p>.05. Hal ini memberi arti bahwa tidak ada perbedaan yang signifikan pada intensitas nyeri yang dirasakan oleh responden yang berjenis kelamin perempuan dan laki-laki baik dikelompok yang diberi es batu yang dipak dan kelompok washlap yang dicelup di air es. Setiap individu memiliki respon yang berbeda-beda terhadap rangsangan nyeri.

Jenis kelamin merupakan salah satu faktor utama yang mempengaruhi respon terhadap nyeri. Persepsi nyeri pada perempuan dipengaruhi oleh emosi seperti rasa takut dan cemas. Pada laki-laki lebih dipengaruhi oleh aspek fisik. Perempuan memiliki ambang batas dan toleransi nyeri yang lebih rendah dibanding laki-laki. Namun, kebudayaan juga mempengaruhi respons laki-laki terhadap nyeri. Karena ada kebudayaan yang mengajarkan lakilaki sejak kecil harus kuat dan tidak boleh menangis walaupun merasakan sakit atau nyeri (Daniels \& Nicoll, 2012).

Penelitian ini menunjukkan bahwa intensitas nyeri berdasarkan jenis kelamin tidak menunjukkan adanya perbedaan yang signifikan. Uji t- independent menunjukkan p>.05. Dengan demikian, cryotherapy kering dengan es batu yang di pak dan cryotherapy basah dengan washlap yang dicelup di air es memberi efek pada intensitas nyeri tanpa dipengaruhi oleh perbedaan jenis kelamin.

\section{Kesimpulan}

Aplikasi cryotherapy menggunakan es batu yang dibungkus dalam kantong kain pada area yang akan dilakukan injeksi intrakutas selama 5 menit sebelum dilakukan penyuntikan dapat mengurangi intensitas nyeri yang dirasakan saat penyuntikan. Penggunaan terapi ini disarankan untuk diterapkan pada prosedur penyuntikan intrakutan, karena murah, efektif, dan tidak ada efek samping. Namun penelitian ini hanya melakukan pengukutran intensitas nyeri dengan numerical pain scale, sehingga untuk penelitian selanjutnya disarankan dapat mengembangkan penelitian ini dengan melakukan penilaian terhadap nyeri dengan alat ukur lain seperti verbal rating scale atau painaid scale.

\section{Daftar Pustaka}

Attia, A. A. M., \& Hassan, A. M. (2017). Effect of cryotherapy on pain management at the puncture site of arteriovenous fistula among children undergoing hemodialysis. International Journal of Nursing Sciences. 4 (1), 4651

Belitsky, R. B., Odam, S. J., \& HubleyKozey, C. (1987). Evaluation of the effectiveness of wet ice, dry ice, and cryogen packs in reducing skin temperature. Physical therapy, 67(7). 1080-1084. DOI: $10.1093 / \mathrm{ptj} / 67.7 .1080$

Daniels, R., \& Nicoll, L. H. (2012). Contemporary medical surgical nursing 2nd ed, USA: Delmar Cengange Learning

El-Deen, A. S. \& Youssef, N. F. A. (2018). The effect of cryotherapy application before versus after subcutaneous anticoagulant injection on pain intensity and hematoma formation: a quasiexperimental design. International Journal of Nursing Sciences, Jul 2018, 5 (3); 223-229

Fikri, R, \& Khusnal E. (2011). Pengaruh kompres dingin terhadap intensitas nyeri pada bayi saat imunisasi di puskesmas Piyungan Bantul. Naskah publikasi, Availabale at: digilib.unisayogya.ac.id/ 1198/1/NASKAH\%20PUBLIKASI.pdf

Freire, B., Geremia, J., Baroni, B. M., \& Vaz, M. A. (2016). Effects of cryotherapy methods on circulatory, 
metabolic, inflammatory and neural prperties: a systemic review. Fisioter.Mov. 29 (2).

Guillot X, Tordi N, Mourot L, Demougeot C, Dugue B, Prati C, Wendling D. (2014). Cryotherapy in inflammatory rheumatic diseases: a systematic review. Expert Review of Clinical Immunology; 10(2): 281-294.

Hoens, A. \& Paul, M. (2013). Cryotherapy: when, why and how. Retrieved from: https://physicaltherapy. med.ubc.ca/files/2013/09/CryotherapyEvidence-informed-practice.pdf

Indriyani, P. Hayati, H., \& Chodidjah, S. (2013). Kompres dingin dapat menurunkan nyeri anak sekolah saat pemasangan infus. Jurnal Keperawatan Indonesia, 16(2). 93-100

Leventhal, L. C., Cianchi, R. C., \& de Oliveira, S. M. J. V. (2010). Clinical trial comparing three types of cryotherapy in non-pregnant women. Rev. esc. enferm. USP. $\quad 44$ (2). Availabel at: http://dx.doi.org/10.1590/S008062342010000200014

Lynn P. (2011) Fundamentals of nursing: The art and science of nursing care. Philadelphia: Lippincott Williams \& Wilkins.

Macqueen S., Bruce E.A. and Gibson F. (2012). The Great Ormond Street Hospital Manual of Children's Nursing Practices, Wiley-Blackwell, Oxford.

Mahshidfar, B., Shevi, S. C., Abbasi, M., Kasnavieh, M. H., Rezai, M., Zavereh, M., \& Mosaddegh, R. (2016). Ice reduces needle-stick pain associated with local anasthetic injection. Anesthesiology and Pain Medicine, Oct 2016, 6 (5); doi: 10.5812/aapm.38293

Mubarak, I., Indrawati, L., \& susanto, J. (2015). Buku Ajar Ilmu Keperawatan dasar. Buku 2. Jakarta: Salemba Medika

Nurachmah, E. (2017), Dasar-dasar Anatomi dan Fisiologi, 12 th Indonesian edition, by Elly Nurachmah. Singapore: Elsevier.

Porth, C. M. (2011). Essentials of pathophysiology. China: Wolters Kluwer Health Lippincott William Wilkins

Ramadan, R. H., El-Fouly, Y. A., Sharaf, W. E., Ayoub, A. S. (2016). Effect of cryotherapy on pain intensity among adult patients receiving intramuscular injections. IORS Journal of Nursing and Health Science. 5 (2)

Ramdhanie, G. G. \& Nugraha, B. A. (2018). Kompres dingin menggunakan cool pack efektif menurunkan nyeri saat tindakan pungsi vena pada anak usia sekolah. Prosiding Seminar Nasional dan Diseminasi Peneltian Kesehatan STIKes Bakti Tunas Husada Tasik Malaya, 21 April 2018

Ramos, G. V., Pinheiro, C. M., Messa, S. P., Delfino, G. B., Marqueti, R. C., Salvini, T. F., \& Duriqan, J. L. Q. (2016). Cryotherapy reduces inflammatory response without altering muscle regeneration process and extracellular matrix remodeling of rat muscle. Science Reports, Jan 2016, 6:18525

Rastogi, A. (2018). Physiologycal effects of cryotherapy: a systematic review. Indian Journal of Applied Research, may-2018, 8 (5)

Rivera, J., Tercero, m. J., Salas, J. S., Gimeno, J. H., \& Alejo, j. S. (2018). The effect of cryotherapy on fibromyalgia: a randomized clinical trial carried out in a crysauna cabin. Rheumatology International, 2018, 38 9120; 22432250. doi: $10.1007 / \mathrm{s} 00296-018-4176-0$

Sharma, V. K., \& K. S. (2009). Guidelines for cryotherapy. Indian J. Dermatol venereol Leprol. 2009; 75 (2)

Stanek, A., Cholewka, A., Wielkoszynski, T., Romuk, E., \& Sieron, A. (2018). Whole-body cryotherapy decrease the 
levels of inflammatory, oxidative stress, and atherosclerosis plague markers in male patients with active-phase ankylosisng spondylitis in the absence of clasical cardiovascular risk factors. Mediators of inflammation, Feb 2018: doi: $10.1155 / 2018 / 8592532$

Sutanto, A. V., \& Fitriana, Y. (2017). Kebutuhan Dsar Manusia: Teori dan Aplikasi dalam Praktek Keperawatan Profesional. Yogyakarta: Pustaka Baru Press
Vargens, O. M. C., Nunes, S., da Silva, L. D., \& Progianti, J. M. (2016). Pain relief effect of cryotherapy in parturients. International Journal of Childbirth, 6 (3). DOI:10.1891/2156-5287.6.3.149

Wright, S., Yelland, M., Heathcote, K., Ng, S. K., \& Wright, G. (2009). Fear of needles-nature and prevalence in general pactice. Aus Fam Physician, 2009 Mar; 38(3):172-6 